\title{
Identification and Implications of Trimethyl-n-Alkylbenzenes in Marine Oils from the Deep Tarim Basin
}

\author{
Wanglu Jia $\mathbb{C}^{1}{ }^{1}$ Yangen Huang, ${ }^{2}$ Zhongyao Xiao, $^{3}$ and Ping'an Peng ${ }^{1,4}$ \\ ${ }^{1}$ State Key Laboratory of Organic Geochemistry, Guangzhou Institute of Geochemistry, Chinese Academy of Sciences, \\ Guangzhou 510640, China \\ ${ }^{2}$ College of Chemistry, Chemical Engineering and Biotechnology, Donghua University, Shanghai 201620, China \\ ${ }^{3}$ Tarim Oilfield Company, PetroChina, Kuerle 841000, China \\ ${ }^{4}$ College of Earth and Planetary Sciences, University of Chinese Academy of Sciences, Beijing 100049, China \\ Correspondence should be addressed to Wanglu Jia; wljia@gig.ac.cn
}

Received 2 September 2020; Revised 4 November 2020; Accepted 9 November 2020; Published 27 November 2020

Academic Editor: Liu Quanyou

Copyright (c) 2020 Wanglu Jia et al. This is an open access article distributed under the Creative Commons Attribution License, which permits unrestricted use, distribution, and reproduction in any medium, provided the original work is properly cited.

\begin{abstract}
The source of marine oils from the deep Tarim Basin is still in debate due to several alteration processes of source indicators. A series of trimethyl-alkylbenzenes has been detected in marine oils from this old, composite basin, besides the reported aryl isoprenoids with 2,3,6-trimethyl substitution (AIPs). They are characterized by regular gas chromatography elution pattern, which is similar to that of $n$-alkylbenzenes, and suggest a strong possibility of $n$-alkyl side chains. $\mathrm{C}_{15}$ trimethyl- $n$-alkylbenzenes were synthesized by Friedel-Crafts acylation of trimethylbenzene isomers to determine their structures. Based on the chromatography and mass spectra data and the coinjection of synthesized compounds, this series of compounds has been assigned as the 2,4,5-trimethyl- $n$-alkylbenzenes that coeluted with 2,3,5-trimethyl- $n$-alkylbenzenes, and other trimethyl- $n$ alkylbenzene isomers were also detected. This series of trimethyl- $n$-alkylbenzene (AAs) shows much higher relative abundances in light and waxy oils than in normal and heavy oils, which is opposite to the variation in relative abundances of aryl isoprenoids. The ratios of these trimethyl- $n$-alkylbenzenes to the aryl isoprenoids (AA/AIP ratio) generally show a good correlation with the maturity indicators for most of studied oils despite of some outliers (mainly condensates). The pyrolysis of asphaltenes has confirmed these trends. These results support an important control of thermal stress on the molecular compositions of marine oils from the deep Tarim Basin, besides other secondary alteration processes (such as oil mixing and migration fractionation, among others). These factors should be given a full consideration for the source determination of deep and ultradeep oils.
\end{abstract}

\section{Introduction}

Aryl isoprenoids (AIPs) with various trimethyl substitution patterns, e.g., 2,3,6-, 2,3,4-, and 3,4,5-trimethyl, exist in sediments and oils and are thought to be the diagenetic products of pigments of photosynthetic sulfur bacteria or algae [1-8]. The source of these novel monoaromatic compounds can be determined based on their carbon isotopic signatures [2, 5-7, 9-11], and the depositional environment for the oil and the sediment source can be characterized. For example, AIPs that are characterized by a significant enrichment in ${ }^{13} \mathrm{C}$ suggest a major contribution from green sulfur bacteria Chlorobiaceae and can be used as an indicator for photic-zone anoxia. These compounds can also be bound into geological macromolecules, such as kerogens, resins, and asphaltenes $[5,6,12,13]$. The AIR ratio (the proportion of short-chain $\mathrm{C}_{13-17}$ versus intermediate-chain $\mathrm{C}_{18-22}$ AIPs) in the sediments has been used to indicate the degree and persistence of photic-zone anoxia [14]. The source of marine oils from the Tarim Basin of China has long been in a debate, due to both multiple source strata and resulted multiple oil charging processes and several secondary oil alteration processes 
[15]. The detection of AIPs with 2,3,6-trimethyl substitution in the oil and highly abundant 1,2,3,4-tetramethylbenzene (TTMB) in oil asphaltene pyrolysates, along with the carbon isotope values of TTMB, has suggested a euxinic depositional environment of the oil source $[12,13,16]$.

Previous studies have also noted that the relative abundances of AIPs are sensitive to the maturity of sediments and oils. Ratios of $\mathrm{C}_{30}$ or $\mathrm{C}_{18}$ AIPs with 2,3,6-trimethyl substitution pattern relative to $\mathrm{C}_{40}$ diaromatic carotenoids show a good correlation with the $\mathrm{C}_{17} n$-alkane/pristane $\left(n-\mathrm{C}_{17} / \mathrm{Pr}\right)$ and $\mathrm{C}_{18} n$-alkane/phytane $\left(n-\mathrm{C}_{18} / \mathrm{Ph}\right)$ ratios that increase progressively with elevated oil maturity, and their abundances decrease rapidly after the source rocks entered the oil window $[4,7]$. The abundances of AIPs in oils decrease with the maturity $[7,17]$, and the short-chain homologues of AIPs become more pronounced with increasing maturity compared with the long-chain homologues [3, 16, 17]. Moreover, the diagnostic products released from the flash pyrolysis of these structures bound to the kerogens, namely, 1,2,3,4tetramethylbenzene (TTMB), is less abundant at the relatively higher maturity level, and the dominance of TTMB in $\mathrm{C}_{4}$ alkylbenzenes will no longer be observed on the pyrolysates of type II kerogens when their Ro values are greater than $0.7 \%$ [18]. A similar result was also reported in the aromatic fraction of oils from the Tarim Basin [17].

In this study, a series of alkylbenzenes has been identified from marine oils in the Tarim Basin along with AIPs, through further examination of the $\mathrm{m} / z \quad 133+134$ mass chromatograms of aromatic fractions of the previously studied oils [19]. The regular gas chromatographic (GC) elution pattern and mass spectra of these alkylbenzenes combined with the coinjection of synthesized reference compounds in the aromatic fraction of one oil sample allowed us to assign this series of alkylbenzenes as 2,4,5-trimethyl- $n$-alkylbenzenes with coelution of 2,3,5trimethyl-substituted isomers. Variations in the ratios of these trimethyl- $n$-alkylbenzenes to AIPs show a similar tendency to that in the ratios of $n$-alkanes to isoprenoids and the AIR ratio, which has been attributed to the oil maturity effect. These results are further supported by an oil asphaltene pyrolysis and thus reinforce the critical influence of thermal maturity on the source-indicating parameters of deep oils, which is worthy of a full consideration for the oil source determination of this basin.

\section{Geological Background}

The geological background and details of the investigated 34 oil samples are given by Jia et al. [19]. Briefly, the Tarim Basin in northwest China is one of the largest oil/gas-prone basins in China. Two source units were identified in the basin including the Cambrian-Lower Ordovician and MiddleUpper Ordovician strata. The source and genesis of marine oils have attracted the attention of Chinese organic geochemists over the past two decades $[16,17,20-30]$ due to the multiple hydrocarbon charge events related with two sets of source rocks. The Cambrian-Lower Ordovician strata were interpreted to be the main source rocks using a detailed oilsource correlation [15]. This finding is supported by recent exploration advances of ultradeep Lower-Middle Cambrian reservoirs in the basin [31-33].

Marine oils in this basin were discovered mainly in Ordovician carbonate and Carboniferous clastic reservoirs, and some were found in Silurian, Triassic, and Jurassic clastic strata. The oils show great diversity of physical properties, and heavy, normal, waxy, and light oils were all found in the production zone. The studied oil samples have various types and were collected from reservoirs of different ages in the two main tectonic units (Tabei and Tazhong uplifts). Geochemical and isotopic characteristics of the oils show large variations, and these samples were classified into two distinct groups using biomarkers, carbon, and hydrogen isotopic compositions of $n$-alkanes [19].

\section{Experimental Techniques}

Routine procedures for the molecular and compoundspecific isotopic analysis of oil can be found in Jia et al. [19]. One oil asphaltene sample has been isothermally pyrolyzed for $72 \mathrm{~h}$ at five different temperatures $\left(260-380{ }^{\circ} \mathrm{C}\right)$ in vacuumed glass tubes, and the variations in the hydrogen isotopic compositions of released $n$-alkanes have been investigated by Jia et al. [34].

The trimethylhexylbenzenes were synthesized by Friedel-Crafts acylation with 1,3,5-, 1,2,4-, and 1,2,3-trimethylbenzenes as the starting material, followed by reduction with sodium borohydride. Briefly, hexanoic acid was used to react with thionyl dichloride to form hexanoyl chloride, which was then reacted with three isomers of trimethylbenzene catalyzed by $\mathrm{AlCl}_{3}$ to yield trimethyl-substituted hexanophenones. The trimethyl-substituted hexanophenones were reduced to trimethyl-substituted $n$-hexylbenzene by sodium borohydride in the presence of $\mathrm{AlCl}_{3}$ in tetrahydrofuran. The trimethyl- $n$-hexylbenzene isomers were purified by flash chromatography and characterized by ${ }^{1} \mathrm{H}$-nuclear magnetic resonance $\left({ }^{1} \mathrm{H}-\mathrm{NMR}\right.$, Bruker AM-400 spectrometer) with tetramethylsilane as an internal standard in deuterated chloroform.

Aromatic fractions of a few selected oil samples were chromatographed using $\mathrm{Al}_{2} \mathrm{O}_{3}$ (100-200 mesh) to eliminate possible influences from polycyclic aromatic hydrocarbons on the alkylbenzene mass spectrum. The monoaromatic fractions were eluted with $n$-hexane/dichloromethane mixture (99:1, v/v) and analyzed using a Thermo DSQII mass spectrometer to which a Trace ultra GC was interfaced, and a $60 \mathrm{~m}$ HP5 capillary column $(0.32 \mathrm{~mm}$ i.d. and $0.25 \mu \mathrm{m}$ film thickness) was used for the separation of organic compounds. Analysis was conducted using both selective ion monitoring (SIM) and full scan detection.

\section{Results and Discussion}

4.1. Occurrence and Mass Spectral Characteristics. Typical AIPs (see Figure 1) detected in the Tarim marine oils were confirmed to have a 2,3,6-trimethyl substitution pattern by comparing them with those in oils from the Peace River Basin of Canada [35] (kindly provided by Prof. R.E. Summons). This series of compounds can be recognized easily 


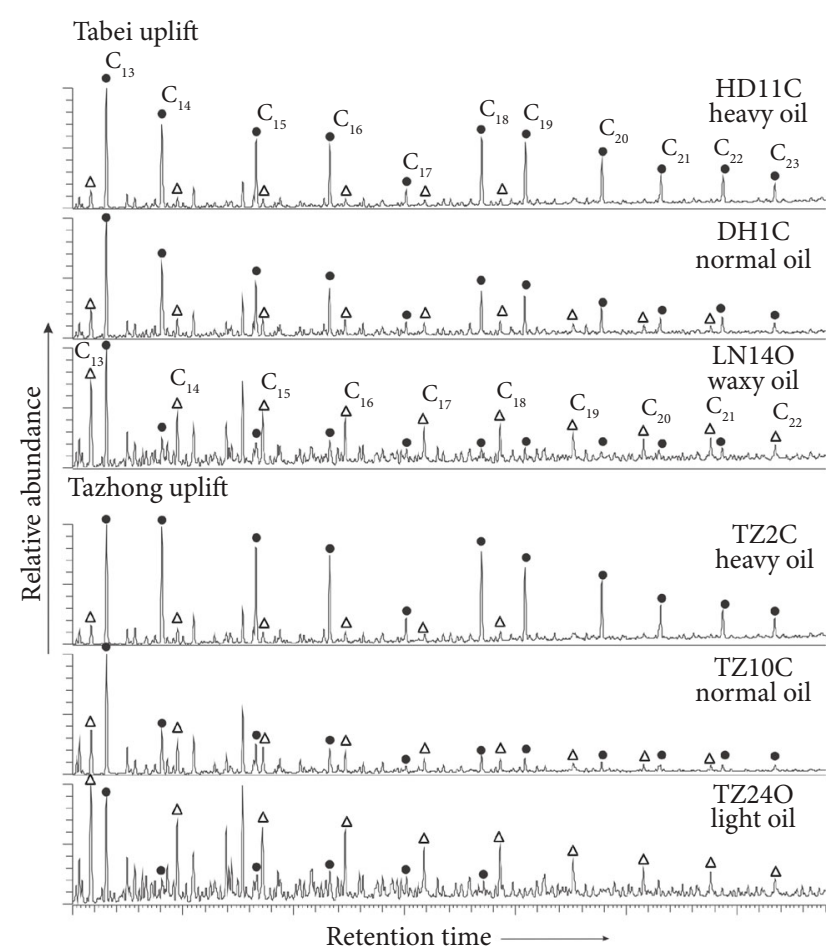

FIgURE 1: Mass chromatograms $(\mathrm{m} / \mathrm{z} 133+134)$ of aromatic fractions of selected oil samples showing AIP and AA distributions. Filled circles indicate AIPs, and unfilled triangles indicate newly identified AAs.

by the unusual low abundance of the $\mathrm{C}_{17}$ homologue and increased intervals of the retention time between the $\mathrm{C}_{14}$ and $\mathrm{C}_{15}$ homologues and between the $\mathrm{C}_{19}$ and $\mathrm{C}_{20}$ homologues, which is a result of irregular isoprenoid substitution on the aromatic ring [2]. The total amount of AIPs has been shown to decrease with elevated oil maturity, whereas the relative abundances of short-chain homologues increase with oil maturity or decreasing oil density $[16,17]$. For the investigated 34 oil samples, abundant AIPs were detected frequently in heavy and normal oils, whereas they were detected at trace levels in waxy or light oils except for the $\mathrm{C}_{13}$ homologue (Figure 1). However, some normal oils from the Tazhong uplift also display low relative abundances of AIPs, e.g., oil TZ10C (Figure 1). Other pseudohomologues of the long-chain alkylbenzenes, abbreviated here as aryl alkanes (AAs, Figure 1), are visible in the $m / z 133+134$ mass chromatograms. In general, they show high relative abundances in waxy and light oils, which is opposite to the variations in the relative abundances of AIPs. This newly detected series of alkylbenzenes elutes at regular intervals of retention time in the chromatograms, which suggests that an $n$-alkyl side chain, and not an isoprenoid, connects to the benzene ring (Figure 1).

$n$-Alkylbenzenes and branched alkylbenzenes [36-38] (also termed phenyl alkanes) and 1,2-di-n-alkylbenzenes [39] were also reported to elute at regular retention time intervals. The reported phenyl alkanes in the sediments and oils generally have a single-branched alkyl side chain on the benzene ring, and no additional methyl groups have been found on the benzene ring [36-38]. Therefore, except for the 2-phenyl alkanes that show a base peak at $m / z 105$ in their mass spectra, other isomers of phenyl alkanes are characterized by a base peak at $m / z 91$ in their mass spectra. 1,2-Di- $n$ alkylbenzenes show a base peak at $m / z 105$ in their mass spectra, except for ethyl- $n$-alkylbenzenes that show a base peak at $\mathrm{m} / z \quad 119$ [39]. Two isomers of $\mathrm{C}_{15}$ trimethylhexylbenzenes detected from a coal-bed wax show mass spectra with a base peak at $m / z 133$ [40], and $\mathrm{C}_{22}$ 2-ethyl-4and 2-ethyl-6-methyl- $n$-alkylbenzenes also show a base peak at $m / z$ 133. Then, Guthrie [9] identified 2-ethyl-4/6-methyl$n$-alkylbenzenes from the Ordovician shale samples containing abundant G. prisca. They show mass spectra with a base peak at $\mathrm{m} / z 133$ and also highly abundant fragment ions at $\mathrm{m} / \mathrm{z} 105$ and 119. These two series of compounds are characterized by high abundances of $\mathrm{C}_{20}$ and $\mathrm{C}_{22}$ homologues, which may be related to the contribution from G. prisca. The newly detected AAs from the Tarim oils can therefore be trimethyl- $n$-alkylbenzenes, as indicated by the base peak at $m / z 133$, the very low relative abundances of the fragment ions at $m / z 105$ and $m / z 119$ in their mass spectra (Figure 2(a)), and by the regular intervals of elution time (Figure 1).

AAs could be distinguished from the AIPs by a much lower relative intensity of the $\mathrm{m} / \mathrm{z} 134$ ion in their mass spectra (Figure 2). An elevated relative intensity of the $\mathrm{m} / \mathrm{z} 134$ ion was observed in the mass spectra of AIPs with increasing length of alkyl side chain, which results from easy $\gamma-\mathrm{H}$ transfer and McLafferty rearrangement [2, 3]. Consistent with these previous results, the mass spectra of AIPs obtained in this work display an elevated relative intensity of the $\mathrm{m} / z 134$ ion with increasing carbon numbers, and the $m / z 134$ ion becomes the base peak on the mass spectrum of $\mathrm{C}_{20}$ AIP (Figure 2(b)). A progressively elevated intensity of the $\mathrm{m} / z 134$ ion with increasing side chain length was also observed in the mass spectra of AAs, which is similar to AIPs. However, the $m / z 133$ ion is always the base peak for AAs from $\mathrm{C}_{13}$ to $\mathrm{C}_{20}$. The $n$ alkyl side chain linked to the benzene ring can suppress the $\gamma-\mathrm{H}$ transfer and McLafferty rearrangement relative to the isoprenoid side chain. The methyl position on the benzene ring also affects the relative intensity of fragment ions of trimethyl-alkylbenzenes. Methyl substitution on the para- and ortho- position can suppress the hydrogen transfer reaction [2], and accordingly, two isomers of AIPs with methyl on two meta- positions, i.e., 2,3,5-trimethyland 3,4,5-trimethyl AIPs, have the $\mathrm{m} / z \quad 134$ ion as their base peak [2,5]. By contrast, the base peak at $m / z 134$ was not observed in the mass spectra of AAs (Figure 2(b)). Therefore, the characteristic ion at $\mathrm{m} / z 133$ appeared in the mass spectra of these trimethyl- $n$-alkylbenzenes in previous studies and this work may result from the $n$-alkyl side chain and the position of methyl substitution on the benzene ring.

4.2. Distributions of $n$-Alkylbenzenes, Mono/Dimethyl-nAlkylbenzenes, and AAs. Long-chain $n$-alkylbenzenes, together with methyl- and dimethyl-substituted $n$-alkylbenzenes, are one of the most common series of aromatic compounds identified in sediments and oils [17, 39-43]. These 



(a)

AIPs
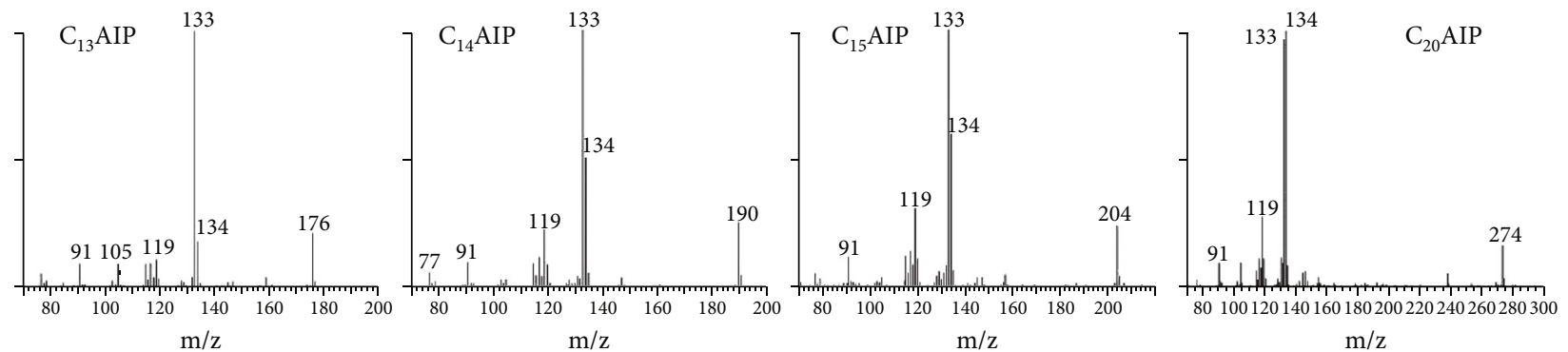

(b)

FIgURE 2: Mass spectra of (a) AAs and (b) AIPs obtained from the monoaromatic oil fractions in the Tarim Basin.

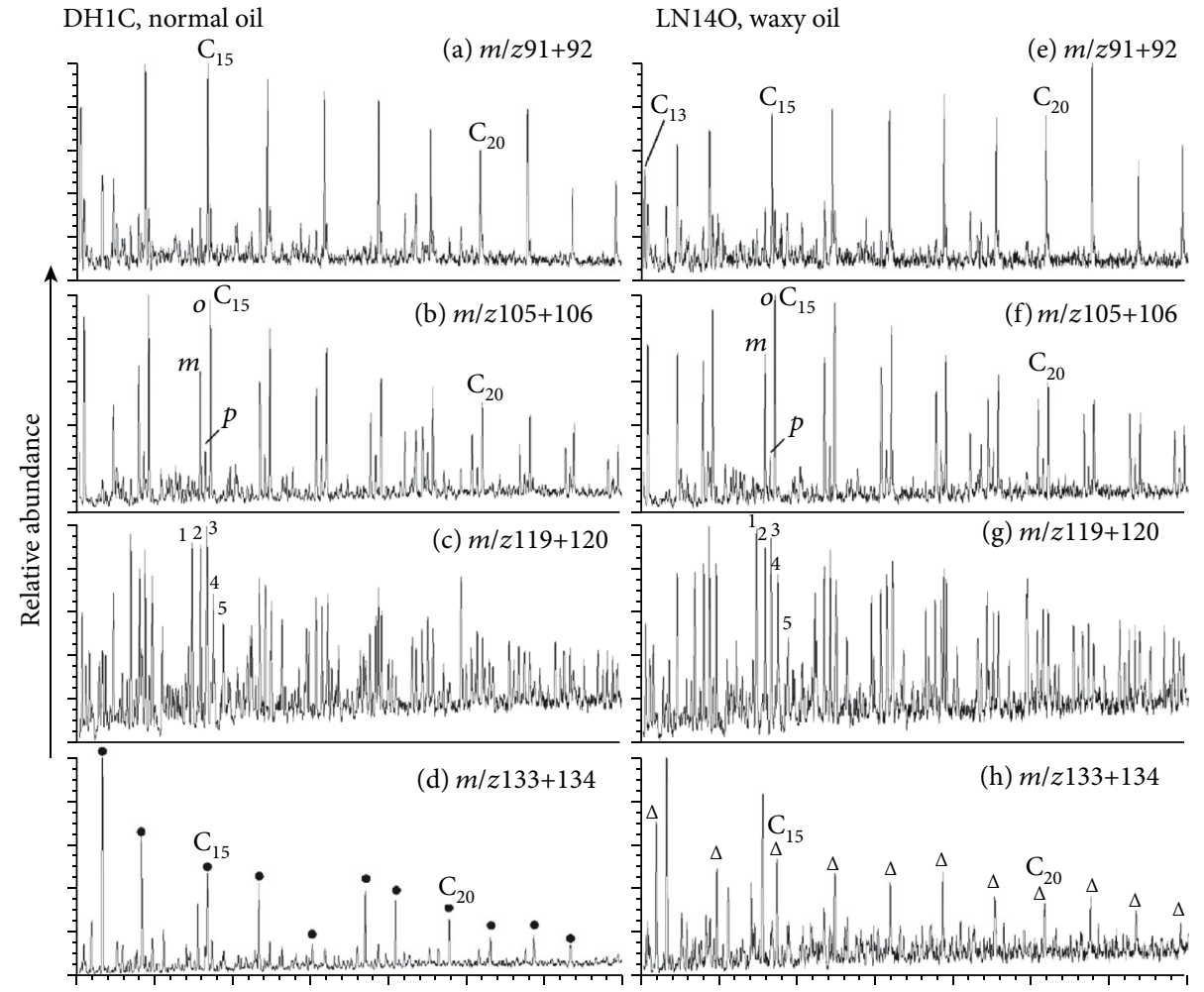

FIGURE 3: $m / z 91+92,105+106,119+120$, and 133+134 mass chromatograms (full scan mode) of the aromatic fractions from the oils (a-d) DH1C and (e-h) LN14O showing the distributions of $n$-alkylbenzene series. The labels $(m, p$, and $o$ ) in (b) and (f) denote the meta-, para-, and ortho isomers of methyl- $n$-alkylbenzene. Numbers 1-5 in (c) and (g) denote 3,5-, 2,5-, 2,4-, 3,4-, and 2,3-dimethyl isomers of dimethyl- $n$ alkylbenzene. The 2,6-dimethyl isomer elutes shortly after the 3,4-dimethyl isomer and exists in very low abundance (structure assignment was made according to the result of Ellis et al. [37]). Filled circles and unfilled triangles in (d) and (h) indicate AIPs and AAs, respectively.

three series of compounds could be detected in both oil samples containing abundant AIPs and those containing AAs (Figure 3). For methyl- $n$-alkylbenzenes, the meta- and ortho- methyl isomers were detected in much higher abundance relative to the para- methyl isomer (Figures $3(\mathrm{~b})$ and $3(\mathrm{f})$ ). Among the six isomers of dimethyl- $n$-alkylbenzenes, the 


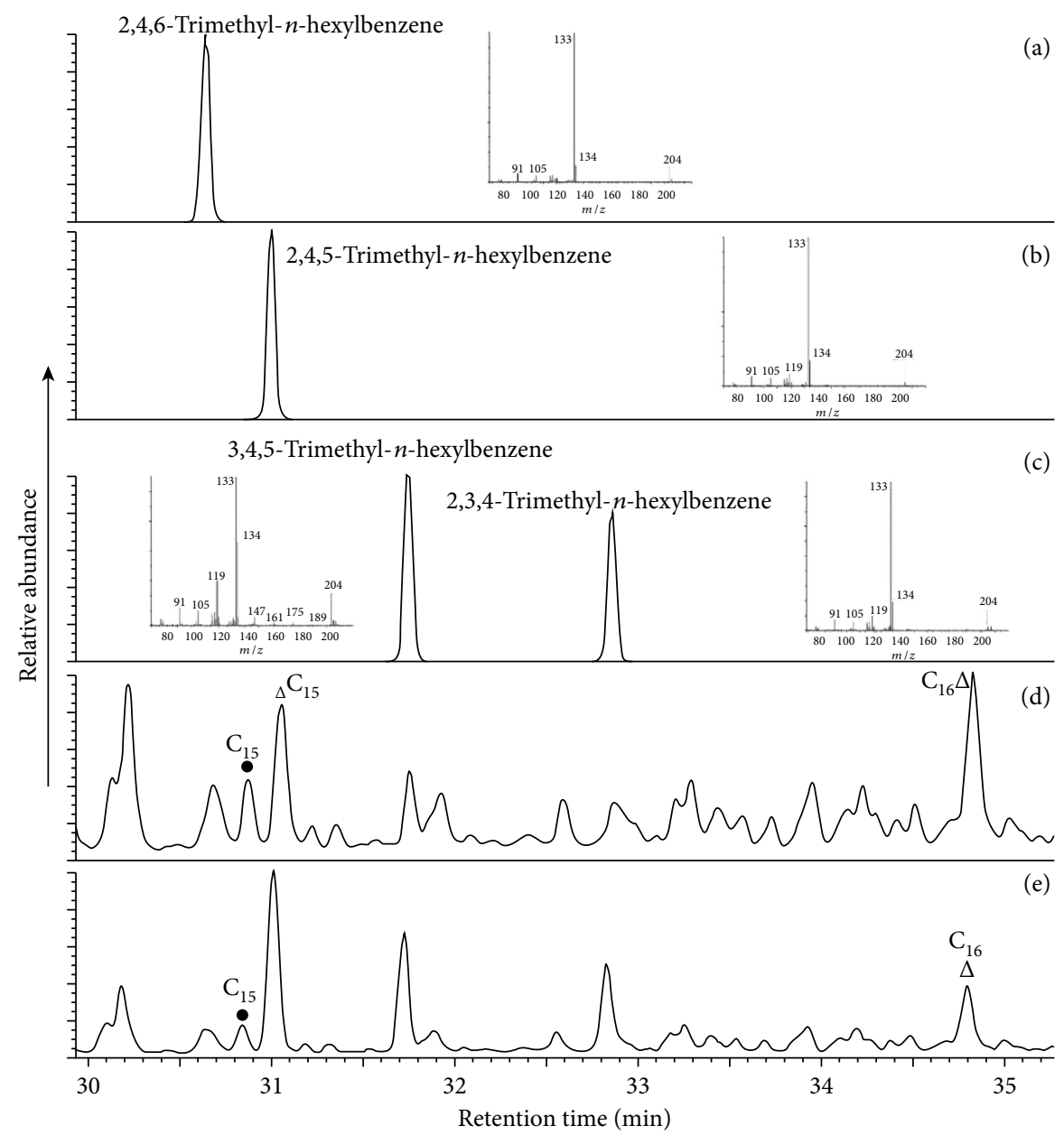

FiguRE 4: $m / z$ 133+134 mass chromatograms of the four synthesized isomers of $(\mathrm{a}-\mathrm{c})$ trimethyl- $n$-hexylbenzene and the $(\mathrm{d}, \mathrm{e}) \mathrm{C}_{15}$ and $\mathrm{C}_{16}$ AAs (unfilled triangles) in the aromatic fraction of oil sample (LN14O in Figure 1) before and after the coinjection of synthesized compounds. Filled cycles denote $\mathrm{C}_{15}$ AIP.

TABLE 1: ${ }^{1} \mathrm{H}$-NMR data for trimethyl- $n$-hexylbenzenes. Shifts are the $\delta$ values in deuterated chloroform. The spectrums can be found in the supplementary material.

\begin{tabular}{|c|c|c|c|c|}
\hline $\begin{array}{l}\text { Methyl substitution } \\
\text { pattern }\end{array}$ & $\mathrm{Ar}-\mathrm{H}$ & $\mathrm{Ar}-\mathrm{CH}_{3}$ & $\mathrm{Ar}-\mathrm{CH}_{2}-$ & $-\mathrm{CH}_{3}$ \\
\hline $2,4,6$ & $\mathrm{~s}, 6.82,2 \mathrm{H}$ & s, $2.28,6 \mathrm{H} ; \mathrm{s}, 2.24,3 \mathrm{H}$ & $\mathrm{t}, 2.55,8.0 \mathrm{~Hz}, 2 \mathrm{H}$ & $\begin{array}{c}\mathrm{t}, 0.90,7.0 \mathrm{~Hz}, \\
3 \mathrm{H}\end{array}$ \\
\hline $2,4,5$ & $\begin{array}{c}\mathrm{s}, 6.89,1 \mathrm{H} ; \mathrm{s}, 6.90 \\
1 \mathrm{H}\end{array}$ & $\mathrm{s}, 2.23,3 \mathrm{H} ; \mathrm{s}, 2.20,3 \mathrm{H} ; \mathrm{s}, 2.19,3 \mathrm{H}$ & $\mathrm{t}, 2.51,8.0 \mathrm{~Hz}, 2 \mathrm{H}$ & $\begin{array}{c}\mathrm{t}, 0.89,6.8 \mathrm{~Hz} \\
3 \mathrm{H}\end{array}$ \\
\hline $3,4,5+(2,3,4)$ & $\begin{array}{c}\mathrm{s}, 6.83,2 \mathrm{H}+(\mathrm{AB} \\
6.91,2 \mathrm{H})\end{array}$ & $\begin{array}{c}\mathrm{s}, 2.26,6 \mathrm{H} ; \mathrm{s}, 2.13,3 \mathrm{H}+(\mathrm{s}, 2.26,3 \mathrm{H} ; \mathrm{s}, 2.21,3 \mathrm{H} ; \\
\mathrm{s}, 2.19,3 \mathrm{H})\end{array}$ & $\begin{array}{c}\mathrm{t}, 2.49,8.0 \mathrm{~Hz}, 2 \mathrm{H}+(\mathrm{t}, 2.58 \\
8.0 \mathrm{~Hz}, 2 \mathrm{H})\end{array}$ & $\begin{array}{c}\mathrm{t}, 0.88,7.0 \mathrm{~Hz}, \\
3 \mathrm{H}\end{array}$ \\
\hline
\end{tabular}

relative abundances of 3,5-, 2,5-, 2,4-, and 3,4-dimethyl isomers are much higher than those of 2,3-dimethyl isomer (Figures 3(c) and 3(g)). These results are consistent with those reported by Ellis et al. [43].

Several previous studies have detected trimethyl- $n$-alkylbenzenes in sediments and oils. For example, $n$-pentylbenzene elutes before all six trimethyl-ethylbenzene isomers $\left(\mathrm{C}_{11}\right)$, and the elution order for the six trimethylethylbenzene isomers was also reported for the pyrolysates of kerogen [5]. In this work, the $\mathrm{C}_{13}$ homologue of the AAs elutes slightly later than the $C_{13} n$-alkylbenzene, and with increasing carbon number, the difference in elution time between the AAs and $n$-alkylbenzenes decreases rapidly (Figures 3(e) and 3(h)). Individual long-chain 2,3,6-trimethyl- $n$-alkylbenzenes have been reported in coal, oils, and shales $[41,44]$. A series of long-chain trimethyl- $n$-alkylbenzenes were detected from coal-bed wax, but the precise structure of this series was not determined [40]. Up to now, the distributional characteristics of six possible isomers of long-chain trimethyl- $n$-alkylbenzenes $\left(\mathrm{C}_{13+}\right)$ are still not well understood, and the structures of the AAs in the Tarim oils thus need to be determined. 


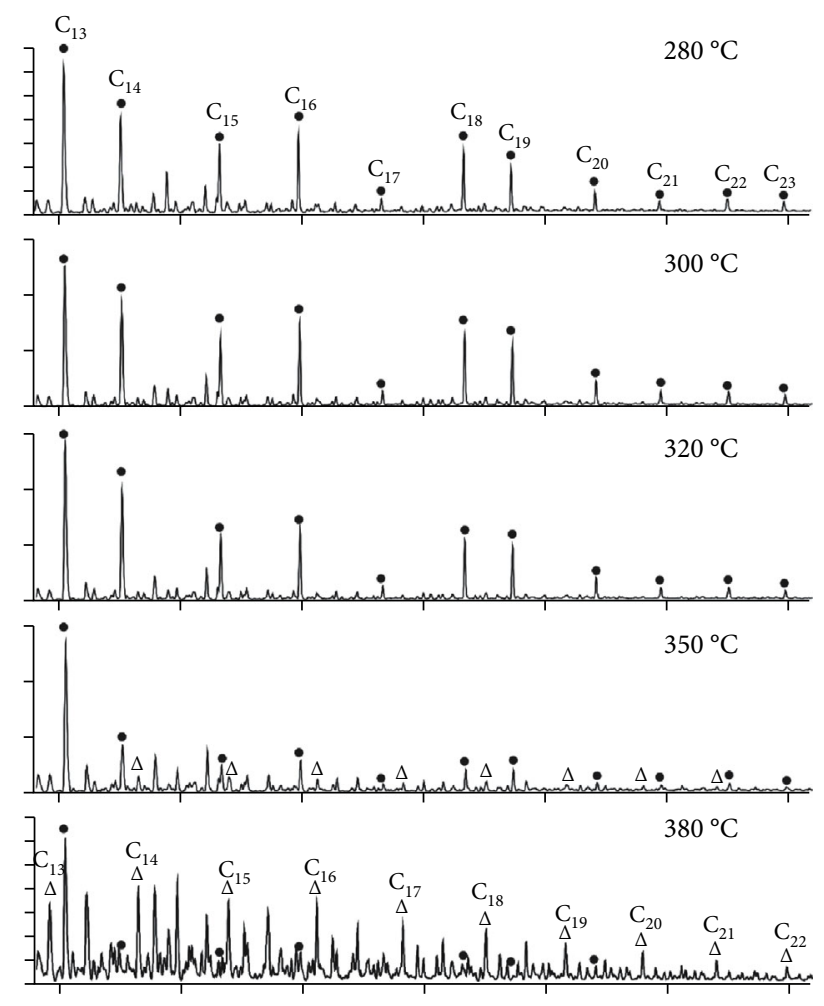

FIGURE 5: $\mathrm{m} / \mathrm{z} 133+134$ mass chromatograms of the aromatic fractions separated from asphaltene pyrolysates at different temperatures. Filled circles indicate AIPs, and unfilled triangles indicate newly identified AAs. The mass chromatogram of the pyrolysates obtained at $260{ }^{\circ} \mathrm{C}$, which is almost the same as those at $280{ }^{\circ} \mathrm{C}$ and $300{ }^{\circ} \mathrm{C}$, was not shown here.

4.3. Synthesized Isomers of Trimethyl-n-Hexylbenzene. When 1,3,5-trimethylbenzene (TMB) was used as the starting material, only the 2,4,6-trimethyl- $n$-hexylbenzene could be detected, as expected according to the Friedel-Crafts acylation reaction routes (Figure $4(\mathrm{a})$ ). When 1,2,4-TMB was used as the starting material, three isomers could be formed in theory, namely, 2,4,5-, 2,3,5-, and 2,3,6-trimethyl- $n$-hexylbenzenes. However, only one isomer was obtained after the reaction (Figure $4(\mathrm{~b})$ ). For the 1,2,3-TMB, two possible isomers, i.e., 3,4,5- and 2,3,4-trimethyl- $n$-hexylbenzenes, were all obtained (Figure $4(\mathrm{c})$ ). ${ }^{1} \mathrm{H}-\mathrm{NMR}$ data for these compounds are listed in Table 1. Only the mixed isomers obtained from 1,2,3-TMB (Figure 4(c)) show a sufficient difference in chemical shift of the aromatic protons for the $7 \mathrm{~Hz}$ ortho coupling, which may indicate the existence of an isomer with 2,3,4-trimethyl substitution [2].

Hartgers et al. [5] reported the elution order of six isomers of trimethyl-ethylbenzene $\left(C_{11}\right)$, which can be helpful to determine methyl substitution patterns for synthesized compounds with 1,2,4-TMB and 1,2,3-TMB as the starting material. 3,4,5-Trimethyl-ethylbenzene elutes much earlier than 2,3,4-trimethyl-ethylbenzene, and accordingly, the two isomers obtained from 1,2,3-TMB were determined as 3,4,5- and 2,3,4-trimethyl- $n$-hexylbenzenes in the order of increasing elution time (Figure 4(c)). 2,3,6-Trimethyl-ethylbenzene elutes between 3,4,5- and 2,3,4-trimethyl-ethylbenzene; hence, the isomer obtained from 1,2,4-TMB can be



FIgURe 6: Variations in the selected molecular ratios with EasyRo values. The $\mathrm{C}_{13-16} \mathrm{AA} / \mathrm{AIP}$ ratio represents the sum of $\mathrm{C}_{13-16} \mathrm{AA}$ peak area divided by that of $\mathrm{C}_{13-16}$ AIPs; $\mathrm{C}_{17-22}$ AAs were not included due to their identification with less confidence in the relatively low-temperature pyrolysates. The $n-\mathrm{C}_{17} / \mathrm{Pr}$ and $n$ $\mathrm{C}_{18} / \mathrm{Ph}$ ratios were extracted from our previous study [34].

2,4,5- or 2,3,5-trimethyl- $n$-hexylbenzene (Figure 4(b)). As reported by Hartgers et al. [5], 2,4,5- and 2,3,5-trimethylethylbenzenes elute between 2,4,6-trimethyl and 3,4,5methyl-ethylbenzene, and the 2,4,5-isomer could not be well separated from the 2,3,5- isomer. The obtained compound in Figure 4(b) could not be assigned as 2,4,5- or 2,3,5-trimethyl$n$-hexylbenzene based on the elution time.

Since all ortho- and para- positions are substituted by methyl groups, the substitution pattern with 2,4,6-trimethyl can suppress the hydrogen transfer reaction and result in a more pronounced $\mathrm{m} / z 133$ ion in the mass spectra of AIPs relative to methyl substitutions at the 2,4,5,2,3,6, and 2,3,4 positions [2]. As expected, the synthesized 2,4,6-trimethyl$n$-hexylbenzene in this work shows a slightly higher relative intensity of the $m / z 133$ ion compared with the 2,3,4-trimethyl- $n$-hexylbenzenes (Figures $4(\mathrm{a})$ and $4(\mathrm{c})$ ). In contrast, AIPs with substitutions of 2,3,5-/3,4,5-trimethyl, with two meta- positions occupied by the methyl, show the most intense hydrogen transfer reaction and a base peak at $\mathrm{m} / \mathrm{z}$ $134[2,5]$. Consistent with this observation, synthesized 3,4,5-trimethyl- $n$-hexylbenzene shows a much higher relative intensity of the $\mathrm{m} / z 134$ ion relative to 2,4,6-/2,3,4-trimethyl- $n$-hexylbenzenes (Figures $4(\mathrm{a})$ and $4(\mathrm{c}))$. The mass spectrum of 3,4,5-trimethyl- $n$-hexylbenzene still shows a base peak at $m / z 133$ rather than at $m / z 134$, which is distinct from the AIPs with 3,4,5-trimethyl substitutions [5]. Therefore, the isomer obtained from the reaction of $1,2,4-\mathrm{TMB}$ (Figure 4(b)), which shows a very low relative intensity of the $m / z 134$ ion, could be assigned as 2,4,5-trimethyl- $n$-hexylbenzene rather than 2,3,5-trimethyl- $n$-hexylbenzene. This assignment is consistent with the orientation of the FriedelCrafts acylation. In 1,2,4-TMB, there is only one position ortho to one of the methyl groups and para to the other. Electrophilic substitution occurs primarily at this position to afford 2,4,5-trimethyl- $n$-hexylbenzene. The position between 




(a)

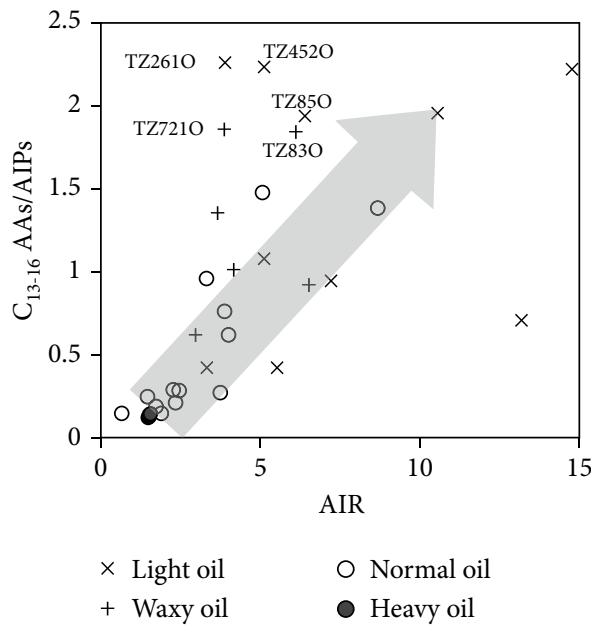

(c)

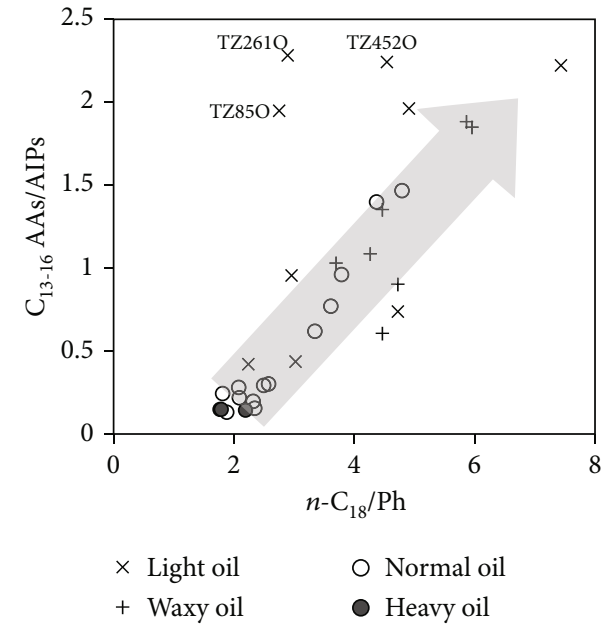

(b)

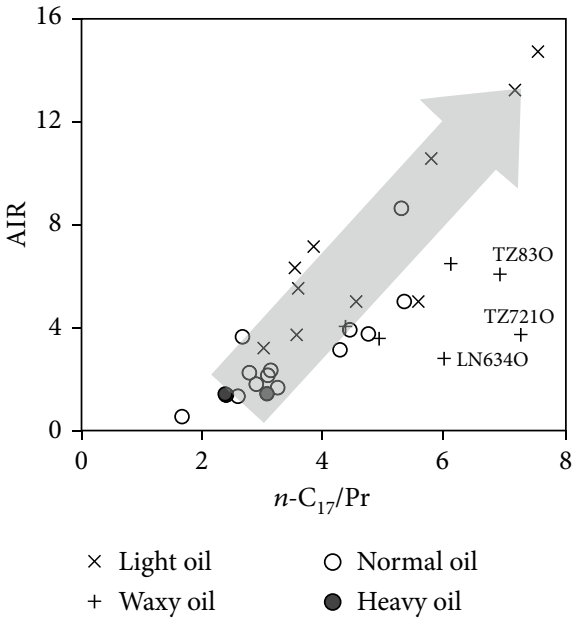

(d)

Figure 7: Cross plots of $\mathrm{C}_{13-16}$ AA/AIP ratio vs. (a) $n-\mathrm{C}_{17} / \mathrm{Pr}$ ratio, (b) $n-\mathrm{C}_{18} / \mathrm{Ph}$ ratio, (c) AIR ratio, and (d) AIR ratio vs. $n$ - $\mathrm{C}_{17} / \mathrm{Pr}$ ratio.

the two methyl groups (ortho to both) is hindered sterically which excludes the formation of 2,3,6-trimethyl- $n$-hexylbenzene. The formation of 2,3,5-trimethyl- $n$-hexylbenzene could also be excluded because the position ortho to one of the methyl groups and meta to the two others in $1,2,4-\mathrm{TMB}$ is less reactive for the Friedel-Crafts acylation.

Except for the 2,4,6-trimethyl- $n$-hexylbenzene, three synthesized compounds were coinjected with the aromatic fraction of oil sample LN14O, and the $m / z \quad 133+134$ mass chromatograms of the aromatic fraction before and after coinjection are shown in Figures 4(d) and 4(e). Coinjection results show that the $\mathrm{C}_{15} \mathrm{AA}$ is possibly the 2,4,5-trimethyl$n$-hexylbenzene, and 3,4,5- and 2,3,4-trimethyl- $n$-hexylbenzenes are also present but in lower abundances relative to 2,4,5-trimethyl- $n$-hexylbenzene. Nevertheless, 2,4,5-trimethyl- $n$-hexylbenzene likely coeluted with 2,3,5-trimethyl$n$-hexylbenzene, as suggested by the previous study [5]. The $\mathrm{C}_{15}$ AA detected in oil samples shows a much higher relative intensity of $\mathrm{m} / z 134$ ion in the mass spectrum (Figure 2(a)) than the synthesized 2,4,5-trimethyl- $n$-hexylbenzene (Figure 4(b)). Therefore, the $\mathrm{C}_{15} \mathrm{AA}$ in the oil could be the 2,4,5-trimethyl- $n$-hexylbenzene that coeluted with 2,3,5-tri- methyl- $n$-hexylbenzene, which made this series of isomer stand out relative to other isomers of trimethyl- $n$ hexylbenzenes.

4.4. Pyrolysis of Oil Asphaltenes. Variations in the relative abundances of alkanes and $\delta \mathrm{D}$ values of $n$-alkanes with increasing pyrolysis temperatures have been reported for the asphaltene pyrolysates [19]; in this study the trimethylalkylbenzene distributions were extracted from the pyrolysates (see Figure 5). The distribution of AIPs in the pyrolysates obtained at $280{ }^{\circ} \mathrm{C}$ and $300{ }^{\circ} \mathrm{C}$ is similar to that in heavy or normal oils shown in Figure 1, as indicating by relatively high abundance of $\mathrm{C}_{18-22}$ AIPs (Figure 5). The relative abundances of $\mathrm{C}_{15-22}$ AIPs decrease at $320{ }^{\circ} \mathrm{C}$, and even the relative abundance of $\mathrm{C}_{14}$ AIPs decreases significantly besides that of $\mathrm{C}_{15-22}$ AIPs at $350{ }^{\circ} \mathrm{C}$. When the pyrolysis temperature was increased to $380{ }^{\circ} \mathrm{C}$, the AIPs could only be detected at trace level except the $\mathrm{C}_{13}$ homologue, but the AAs predominate the trimethyl-alkylbenzenes in the pyrolysates. This feature is similar to those observed on the light or waxy oils in Figure 1. Nevertheless, other isomers of trimethyl- $n$-alkylbenzenes (especially $\mathrm{C}_{13-18}$ homologues), like the 3,4,5- and 
2,3,4-trimethyl- $n$-hexylbenzenes displayed in Figure 4, show notably higher relative abundance in the asphaltene pyrolysates than in oil samples. This discrepancy might result from the differences either in molecular composition between oil asphaltenes and aromatic fraction or in thermal maturation between laboratory and geological conditions.

One of the commonly used thermal maturity indicator (EasyRo) has been calculated according to the reported kinetic parameters [45] and the present pyrolysis procedure, and the variations in selected molecular ratio with thermal maturation level are shown in Figure 6. The relative abundances of short-chain AIPs, denoted by AIR ratio, increase progressively at EasyRo of approximately $0.8 \%$ (close to the oil peak), suggesting that long-chain AIPs began to crack secondarily at this point. By contrast, the relative abundances of trimethyl- $n$-alkylbenzenes (compared with that of aryl isoprenoids, denoted by the $\mathrm{C}_{13-16} \mathrm{AA} / \mathrm{AIP}$ ratio) increase slightly at EasyRo of $1.1 \%$ (shortly after the oil peak) and then increase rapidly when the asphaltenes have evolved into the condensate/wet gas stage. This result is consistent with a dominance of AAs over AIPs in Figure $5\left(380{ }^{\circ} \mathrm{C}\right)$. Similar variation trends could also be observed on the relative abundances of $n$-alkanes compared with acyclic isoprenoids, commonly denoted by the $n-\mathrm{C}_{17} / \mathrm{Pr}$ and $n-\mathrm{C}_{18} / \mathrm{Ph}$ ratios $\left(\mathrm{C}_{17} n\right.$ alkane/pristane and $\mathrm{C}_{18} n$-alkane/phytane, respectively). This result suggests that the aryl isoprenoids may share a similar thermal evolution trend to the acyclic isoprenoids in the saturated fraction of oil, and this thermal evolution is mainly associated with the stability of isoprenoid side chain.

4.5. Variations in the AIPs and AAs in Oils. The $n$-alkylbenzenes and their methyl-substituted series are generally thought to be originated from the cyclization and aromatization of the precursors possessing linear carbon skeletons as well as functionalities, such as the straight-chain fatty acids and alcohols [39, 40, 43]. During the sedimentation and diagenesis, these fatty acids and alcohols could be first reduced to $\alpha$-carbonium ions that generate $n$-alkylbenzenes during the subsequent cyclization and aromatization [40]. If the $\mathrm{H}^{+}$ migration or isomerization of carbonium ions has happened, the cyclization and aromatization products will be methyl- $n$ alkylbenzenes or dimethyl- $n$-alkylbenzenes, respectively [40]. The methyl- $n$-alkylbenzenes in low-maturity oils are usually dominated by the isomer with the ortho-position substituted by methyl, i.e., 2 -methyl- $n$-alkylbenzenes $[39,43]$, which is consistent with its lower formation energy relative to two other isomers [43]. The oil pyrolysis experiments and natural maturation series of oil have further shown that the relative proportions of isomers of (di) methyl- $n$-alkylbenzenes depend on the thermal stabilities in the isomerization reactions, as a result of the elevated thermal stress and the catalysis by clay $[39,43]$. By contrast, the trimethyl- $n$-alkylbenzenes were detected only in a few cases [40], and the structures of two $\mathrm{C}_{15}$ isomers were not determined in their study. Different $n$ alkylbenzene classes in the waxy oil show similar distributions (Figures 3(e)-3(h)), e.g., the same carbon number range and no carbon number preference. These results may suggest that the relatively abundant AAs are the products of the cyclization, aromatization, and isomerization reactions of the precur- sors having linear carbon skeletons. However, one should bear in mind that the AAs are the coelution products of 2,4,5- and 2,3,5-trimethyl- $n$-alkylbenzenes, making them show higher relative abundances than other isomers (Figures 4 and 5).

In the above section, we have shown that the detected AAs are relatively abundant in light oils, waxy oils, and some normal oils, which is generally in contrast with the variation in relative abundances of AIPs in various types of oils (Figure 1). To further explore the maturity effect on the relative abundance of AAs in the oils, the ratios of AAs to AIPs were calculated for the 34 previously investigated oil samples [19]. Biomarkers and isotopic compositions (C, H, and S) of two heavy oils, TZ62S and TD2 $\epsilon$, have been shown to be different from those of most marine oils from the Tarim Basin, and these two oil samples were classified into a unique genetic group [19]. Up to now, their origin and genesis are still not well understood, possibly due to a hydrothermal effect [15]. Therefore, they were not included in the following discussion. Considering the structure similarity, the $n$ $\mathrm{C}_{17} / \mathrm{Pr}, n-\mathrm{C}_{18} / \mathrm{Ph}$, and AIR ratios were used as maturity indicator for oils. It has been demonstrated that the $n-\mathrm{C}_{17} / \mathrm{Pr}$ ratio exhibited excellent linear correlation with the $n$ $\mathrm{C}_{18} / \mathrm{Ph}$ ratio of the majority of marine oils from the Tarim Basin, suggesting a maturity trend of the variations in these ratios $[17,19]$. In addition, the ratio of short-chain $\left(C_{12-17}\right)$ to long-chain $\left(\mathrm{C}_{18-23}\right)$ AIPs, which is similar to the AIR ratio, has been shown to follow a positive correlation to the increasing maturity [17].

Generally, the $\mathrm{C}_{13-16} \mathrm{AA} / \mathrm{AIP}$ ratio increases linearly with elevated $n-\mathrm{C}_{17} / \mathrm{Pr}, n-\mathrm{C}_{18} / \mathrm{Ph}$, and AIR ratios, thus defining a clear maturity trend (Figures $7(\mathrm{a})-7(\mathrm{c})$ ). The light and waxy oils overall have much higher ratios than heavy and normal oils, which is also consistent with the maturity trend of oil density. A few normal oils from the Tazhong uplift have relatively high ratios, which may be indicative of relative high maturity or a mixing of oil from different maturity levels [19]. Notably, a few light oils (condensates) from the Tazhong uplift (such as TZ452O, TZ261O, and TZ85O) possess higher $\mathrm{C}_{13-16} \mathrm{AA} / \mathrm{AIP}$ ratios than most of study samples, making them deviate upwardly from the maturity trend (Figures $7(a)-7(c))$. The exact reason for this discrepancy is not clear yet based on the available data. The mixing of oils from different sources might be one explanation. For example, the light oil TZ452O has been interpreted to be the mixing origin as indicated by its biomarker parameters [19]. However, the source of the light oil TZ85O is still obscure, because of its similarity of both carbon isotopic and biomarker characteristics between those of the majority of heavy and normal oils. Other secondary factors like the thermal sulphate reduction and biodegradation may be possible but need a further investigation.

A few waxy oils (such as TZ721O, TZ83O, and LN634O) have lower AIR ratios than most study samples, causing their deviating downwardly from the maturity trend (Figure $7(\mathrm{~d})$ ). The migration fractionation [46], such as gas washing of precharged oil and later fluid phase changes, is possibly responsible for the deviation. Waxy oils formed by this way are relatively depleted in short-chain hydrocarbons, leading to lower AIR ratios of waxy oils than condensates. By contrast, 
the $\mathrm{C}_{13-16}$ AAs/AIPs, $n-\mathrm{C}_{17} / \mathrm{Pr}$ ratio, and $n-\mathrm{C}_{18} / \mathrm{Ph}$ ratios, representing relative abundances of compound classes with different thermal stabilities but similar elution time (evaporation temperature), could thus be much less affected by the fractionation process.

\section{Conclusions}

A series of trimethyl-substituted alkylbenzenes has been detected in various types of marine oils from the Tarim Basin. Based on their GC elution patterns, mass spectra, and coinjection with synthesized compounds, this series of compounds has been assigned as 2,4,5-trimethyl- $n$-alkylbenzenes that coeluted with 2,3,5-trimethyl-n-alkylbenzenes. Other isomers of trimethyl- $n$-alkylbenzene were also detected. The relative abundances of this series of trimethyl- $n$-alkylbenzenes are usually much higher in the light and waxy oils than in the normal and heavy oils, which is opposite to the variations in relative abundances of AIPs in the oils. Detailed examinations reveal that the ratios of AAs to AIPs of studied oils generally show good correlations with molecular maturity indicators. This maturity trend could also be observed on the pyrolysates of oil asphaltenes with increasing pyrolysis temperature. Therefore, much higher abundance of AAs in these deep oils than those of AIPs can be primarily attributed to higher thermal stability of $n$-alkyl side chain than that of isoprenoids one attached to benzene ring. In addition, the coelution of the two isomers also makes them stand out from the trimethyl- $n$-alkylbenzenes. The AA and AIP deviations of some condensates and waxy oil molecular ratios are likely influenced by other factors like oil mixing and migration fractionation, which may have influenced the relative abundances of AAs and AIPs. Therefore, the effects of thermal stress and other secondary alteration processes on molecular source indicators should be given a full consideration for tracing the source of deep and ultradeep oils.

\section{Data Availability}

The data used to support the findings of this study are available from the corresponding author upon request.

\section{Conflicts of Interest}

The authors declare that there are no conflicts of interest regarding the publication of this paper.

\section{Acknowledgments}

This work was supported by the National Oil and Gas Major Project (2017ZX05008-002), the National Key Research and Development Program of China (2017YFC0603101), the Natural Science Foundation of China (Grant No. 41473044), and the State Key Laboratory of Organic Geochemistry (Grant No. SKLOG2020-1). The authors appreciate Prof. P. Schaeffer for the comments on the structure of synthesized compounds. Special thanks go to Prof. R.E. Summons and Prof. Alex L. Ses- sions for assisting with the confirmation of methyl substitution pattern of AIPs.

\section{Supplementary Materials}

The ${ }^{1} \mathrm{H}$-NMR spectrums of synthesized trimethyl- $n$-alkylbenzenes, with three trimethylbenzene isomers as the starting material, were provided. (Supplementary Materials)

\section{References}

[1] R. E. Summons and T. G. Powell, "Chlorobiaceae in Palaeozoic seas revealed by biological markers, isotopes and geology," Nature, vol. 319, no. 6056, pp. 763-765, 1986.

[2] R. E. Summons and T. G. Powell, "Identification of aryl isoprenoids in source rocks and crude oils: biological markers for the green sulphur bacteria," Geochimica et Cosmochimica Acta, vol. 51, no. 3, pp. 557-566, 1987.

[3] Y. Xinke, F. Pu, and R. P. Philp, "Novel biomarkers found in South Florida Basin," Organic Geochemistry, vol. 15, no. 4, pp. 433-438, 1990.

[4] A. G. Requejo, J. Allan, A. S. Creaney, C. N. Gray, and K. S. Cole, "Aryl isoprenoids and diaromatic carotenoids in Paleozoic source rocks and oils from the Western Canada and Williston basins," Organic Geochemistry, vol. 19, no. 1-3, pp. 245264, 1992.

[5] W. A. Hartgers, J. S. Sinninghe Damsté, A. G. Requejo, and J. Allan, "A molecular and carbon isotopic study towards the origin and diagenetic fate of diaromatic carotenoids," Organic Geochemistry, vol. 22, no. 3-5, pp. 703-725, 1994.

[6] M. P. Koopmans, J. Köster, H. M. E. van Kaam-Peters et al., "Diagenetic and catagenetic products of isorenieratene: molecular indicators for photic zone anoxia," Geochimica et Cosmochimica Acta, vol. 60, no. 22, pp. 4467-4496, 1996.

[7] D. J. Clifford, J. L. Clayton, and J. S. Sinninghe Damsté, "2,3,613,4,5-Trimethyl substituted diaryl carotenoid derivatives (Chlorobiaceae) in petroleums of the Belarussian Pripyat River Basin," Organic Geochemistry, vol. 29, no. 5-7, pp. 1253-1267, 1998.

[8] J. J. Brocks and P. Schaeffer, "Okenane, a biomarker for purple sulfur bacteria (Chromatiaceae), and other new carotenoid derivatives from the 1640 Ma Barney Creek Formation," Geochimica et Cosmochimica Acta, vol. 72, no. 5, pp. 1396-1414, 2008.

[9] J. M. Guthrie, "Molecular and carbon isotopic analysis of individual biological markers: evidence for sources of organic matter and paleoenvironmental conditions in the Upper Ordovician Maquoketa Group, Illinois Basin, U.S.A," Organic Geochemistry, vol. 25, no. 8, pp. 439-460, 1996.

[10] M. P. Koopmans, S. Schouten, and M. E. L. Kohnen, "Restricted utility of aryl isoprenoids as indicators for photic zone anoxia," Geochimica et Cosmochimica Acta, vol. 60, no. 23, pp. 4873-4876, 1996.

[11] K. Grice, P. Schaeffer, L. Schwark, and J. R. Maxwell, "Changes in palaeoenvironmental conditions during deposition of the Permian Kupferschiefer (Lower Rhine Basin, northwest Germany) inferred from molecular and isotopic compositions of biomarker components," Organic Geochemistry, vol. 26, no. 11-12, pp. 677-690, 1997.

[12] W. L. Jia, P. A. Peng, and Z. Y. Xiao, "Carbon isotopic compositions of 1,2,3,4-tetramethylbenzene in marine oil asphaltenes 
from the Tarim Basin: evidence for the source formed in a strongly reducing environment," Science in China D, vol. 51, no. 4, pp. 509-514, 2008.

[13] W. L. Jia, P. A. Peng, C. L. Yu, and Z. Y. Xiao, "Molecular and isotopic compositions of bitumens in Silurian tar sands from the Tarim Basin, NW China: characterizing biodegradation and hydrocarbon charging in an old composite basin," Marine and Petroleum Geology, vol. 27, no. 1, pp. 13-25, 2010.

[14] L. Schwarka and A. Frimmel, "Chemostratigraphy of the Posidonia Black Shale, SW Germany," Chemical Geology, vol. 206, no. 3-4, pp. 199-230, 2004.

[15] H. Huang, S. Zhang, and J. Su, "Palaeozoic oil-source correlation in the Tarim Basin, NW China: a review," Organic Geochemistry, vol. 94, pp. 32-46, 2016.

[16] Y. Sun, S. Xu, H. Lu, and P. Cuai, "Source facies of the Paleozoic petroleum systems in the Tabei uplift, Tarim Basin, NW China: implications from aryl isoprenoids in crude oils," Organic Geochemistry, vol. 34, no. 4, pp. 629-634, 2003.

[17] S. C. Zhang, H. P. Huang, J. Su, M. Liu, and H. F. Zhang, "Geochemistry of alkylbenzenes in the Paleozoic oils from the Tarim Basin, NW China," Organic Geochemistry, vol. 77, pp. 126-139, 2014.

[18] G. P. Lis, M. Mastalerz, and A. Schimmelmann, "Increasing maturity of kerogen type II reflected by alkylbenzene distribution from pyrolysis gas chromatography mass spectrometry," Organic Geochemistry, vol. 39, no. 4, pp. 440-449, 2008.

[19] W. Jia, Q. Wang, P. Peng, Z. Xiao, and B. Li, "Isotopic compositions and biomarkers in crude oils from the Tarim Basin: oil maturity and oil mixing," Organic Geochemistry, vol. 57, pp. 95-106, 2013.

[20] S. C. Zhang, A. D. Hanson, J. M. Moldowan et al., "Paleozoic oil-source rock correlations in the Tarim Basin, NW China," Organic Geochemistry, vol. 31, no. 4, pp. 273-286, 2000.

[21] T. G. Wang, F. He, C. J. Wang, W. B. Zhang, and J. Q. Wang, "Oil filling history of the Ordovician oil reservoir in the major part of the Tahe Oilfield, Tarim Basin, NW China," Organic Geochemistry, vol. 39, no. 11, pp. 1637-1646, 2008.

[22] C. F. Cai, C. M. Zhang, L. L. Cai et al., "Origins of Palaeozoic oils in the Tarim Basin: evidence from sulfur isotopes and biomarkers," Chemical Geology, vol. 268, no. 3-4, pp. 197-210, 2009.

[23] C. Cai, C. Zhang, R. H. Worden et al., "Application of sulfur and carbon isotopes to oil-source rock correlation: a case study from the Tazhong area, Tarim Basin, China," Organic Geochemistry, vol. 83-84, pp. 140-152, 2015.

[24] S. M. Li, X. Q. Pang, Z. J. Jin et al., "Petroleum source in the Tazhong uplift, Tarim Basin: new insights from geochemical and fluid inclusion data," Organic Geochemistry, vol. 41, no. 6, pp. 531-553, 2010.

[25] M. Li, T. G. Wang, P. G. Lillis, C. Wang, and S. Shi, “The significance of 24-norcholestanes, triaromatic steroids and dinosteroids in oils and Cambrian-Ordovician source rocks from the cratonic region of the Tarim Basin, NW China," Applied Geochemistry, vol. 27, no. 8, pp. 1643-1654, 2012.

[26] S. Li, A. Amrani, X. Pang et al., "Origin and quantitative source assessment of deep oils in the Tazhong uplift, Tarim Basin," Organic Geochemistry, vol. 78, pp. 1-22, 2015.

[27] B. Cheng, T. G. Wang, Z. Chen, X. Chang, and F. Yang, "Biodegradation and possible source of Silurian and Carboniferous reservoir bitumens from the Halahatang sub-depression,
Tarim Basin, NW China," Marine and Petroleum Geology, vol. 78, pp. 236-246, 2016.

[28] B. Cheng, H. Liu, Z. Cao, X. Wu, and Z. Chen, “Origin of deep oil accumulations in carbonate reservoirs within the north Tarim Basin: insights from molecular and isotopic compositions," Organic Geochemistry, vol. 139, article 103931, 2020.

[29] X. Pang, J. Chen, S. Li, J. Chen, Y. Wang, and H. Pang, "Evaluation method and application of the relative contribution of marine hydrocarbon source rocks in the Tarim Basin: a case study from the Tazhong area," Marine and Petroleum Geology, vol. 77, pp. 1-18, 2016.

[30] Tenger, Z. J. Jin, Q. Y. Liu, and J. B. Yun, “Potential petroleum sources and exploration directions around the Manjar Sag in the Tarim Basin," Science China Earth Sciences, vol. 60, no. 2, pp. 235-245, 2017.

[31] Z. Wang, H. Xie, Y. Chen, Y. Qi, and K. Zhang, "Discovery and exploration of Cambrian subsalt dolomite original hydrocarbon reservoir at Zhongshen-1 well in Tarim Basin," China Petroleum Exploration, vol. 19, no. 2, pp. 1-13, 2014.

[32] G. Zhu, F. Chen, M. Wang, Z. Zhang, R. Ren, and L. Wu, "Discovery of the lower Cambrian high-quality source rocks and deep oil and gas exploration potential in the Tarim Basin, China," AAPG Bulletin, vol. 102, no. 10, pp. 21232151, 2018.

[33] H. Yang, Y. Cheng, J. Tian et al., "Great discovery and its significance of ultra-deep oil and gas exploration in well Luntan-1 of the Tarim Basin," China Petroleum Exploration, vol. 25, no. 2, pp. 62-72, 2020.

[34] W. Jia, S. Chen, X. Zhu, P. Peng, and Z. Xiao, "D/H ratio analysis of pyrolysis-released n-alkanes from asphaltenes for correlating oils from different sources," Journal of Analytical and Applied Pyrolysis, vol. 126, pp. 99-104, 2017.

[35] L. E. Hays, T. Beatty, C. M. Henderson, G. D. Love, and R. E. Summons, "Evidence for photic zone euxinia through the end-Permian mass extinction in the Panthalassic Ocean (Peace River Basin, Western Canada)," Palaeoworld, vol. 16, no. 1-3, pp. 39-50, 2007.

[36] J. P. Bao, T. G. Wang, J. Y. Wang, and L. L. Jiao, "Identification and geochemistry of a novel phenyl alkane series," Journal of Jianghan Petroleum Institute, vol. 18, pp. 37-41, 1996, (In Chinese with English abstract).

[37] L. Ellis, T. A. Langworthy, and R. Winans, "Occurrence of phenylalkanes in some Australian crude oils and sediments," Organic Geochemistry, vol. 24, no. 1, pp. 57-69, 1996.

[38] J. C. Tuo, R. Chen, M. F. Zhang, and X. B. Wang, “Occurrences and distributions of branched alkylbenzenes in the Dongsheng sedimentary uranium ore deposits, China," Journal of Asian Earth Sciences, vol. 39, no. 6, pp. 770-785, 2010.

[39] J. S. Sinninghe Damsté, A. C. Kock-van Dalen, P. A. Albrecht, and J. W. de Leeuw, "Identification of long-chain 1,2-di-nalkylbenzenes in Amposta crude oil from the Tarragona Basin, Spanish Mediterranean: implications for the origin and fate of alkylbenzenes," Geochimica et Cosmochimica Acta, vol. 55, no. 12, pp. 3677-3683, 1991.

[40] D. Ji-Zhou, W. P. Vorkink, and M. L. Lee, "Origin of longchain alkylcyclohexanes and alkylbenzenes in a coal-bed wax," Geochimica et Cosmochimica Acta, vol. 57, no. 4, pp. 837-849, 1993.

[41] E. J. Gallegos, "Alkylbenzenes derived from carotenes in coals by GC/MS," Journal of Chromatographic Science, vol. 19, no. 4, pp. 177-182, 1981. 
[42] J. A. Williams, D. L. Dolcater, B. E. Torkelson, and J. C. Winters, "Anomalous concentrations of specific alkylaromatic and alkylcycloparaffin components in West Texas and Michigan crude oils," Organic Geochemistry, vol. 13, no. 1-3, pp. 47-60, 1988.

[43] L. Ellis, R. K. Singh, R. Alexander, and R. I. Kagi, "Geosynthesis of organic compounds: III. Formation of alkyltoluenes and alkylxylenes in sediments," Geochimica et Cosmochimica Acta, vol. 59, no. 24, pp. 5133-5140, 1995.

[44] L. Ellis, R. I. Kagi, and R. Alexander, "Separation of petroleum hydrocarbons using dealuminated mordenite molecular sieve. I. Monoaromatic hydrocarbons," Organic Geochemistry, vol. 18, no. 5, pp. 587-593, 1992.

[45] J. J. Sweeney and A. K. Burnham, "Evaluation of a simple model of vitrinite reflectance based on chemical kinetics," AAPG Bulletin, vol. 74, pp. 1559-1570, 1990.

[46] S. C. Zhang, J. Su, X. M. Wang et al., "Geochemistry of Palaeozoic marine petroleum from the Tarim Basin, NW China. Part 3: thermal cracking of liquid hydrocarbons and gas washing as the major mechanisms for deep gas condensate accumulations," Organic Geochemistry, vol. 42, no. 11, pp. 1394-1410, 2011. 